\title{
Analysis of the Break Size Influence on the Damage Accident of Single Heat Transfer Tube of Ship Nuclear Power Steam Generator
}

\author{
Meng Cai*, Wei Wang, Junzhong Sun, Renxi Jin \\ Naval Submarine Academy, Qingdao, China \\ Email: ^13280812878@126.com
}

How to cite this paper: Cai, M., Wang, W., Sun, J.Z. and Jin, R.X. (2017) Analysis of the Break Size Influence on the Damage Accident of Single Heat Transfer Tube of Ship Nuclear Power Steam Generator. World Journal of Engineering and Technology, 5, 21-32.

https://doi.org/10.4236/wjet.2017.54B003

Received: May 27, 2017

Accepted: October 9, 2017

Published: October 12, 2017

\begin{abstract}
In view of the problem that the breakage size is not enough to analyze the damage of the heat transfer tube of the ship nuclear power steam generator under the condition that the breakage loop cannot be isolated, this paper analyzes the damage safety analysis model based on the MELCOR program, Damage of heat transfer tubes at different break sizes $(2 \mathrm{~mm}$ and $6 \mathrm{~mm})$ to reactor power, primary loop pressure, regulator water level, core water level, vapor pressure, break flow, fuel element cladding breakage, etc. The influence of the breakage size on the damage effect of the heat transfer tube has improved the analysis and handling capacity of the damage of the heat transfer tube, and improved the reactor accident handling capacity under the condition of the damage of the heat transfer tube.
\end{abstract}

\section{Keywords}

Steam Generator, Damage Safety Analysis, Break Size

\section{Introduction}

Steam generator is an important ship nuclear power plant, responsible for the heat generated by reactor to the secondary circuit, but its working environment is very bad, heat pipe wall is very thin, but on the wall one or two side heat stress is very large, the heat pipe in the pipe material selection, running water quality, stress factors and other comprehensive role, is very prone to defects, resulting in damage to the heat transfer tube [1]. Once the damage to the heat transfer tube occurs during the reactor operation in the sea, it will cause a large number of radioactive material leakages, to the staff, to the environment, to the equipment, and it will bring great harm [2]. 
In view of the importance of the steam generator and the serious damage of the heat transfer tube, it is necessary to analyze the damage of the heat transfer tube. In order to carry out the influence of the size of the breakage on the damage of the single heat transfer tube, the influence of the damage size on the damage of the heat transfer tube is obtained by the analysis of the two breakage sizes of 2 $\mathrm{mm}$ and $6 \mathrm{~mm}$.

\section{Establishment of Safety Analysis Model for Heat Transfer Tube Breakage}

In order to carry out safety analysis of heat pipe damage, it is necessary to introduce the steam generator modeling; evaporator modeling is divided into primary modeling and secondary modeling [3]. The primary side of the steam generator consists of a high pressure water chamber and a U-shaped tube bundle. The high pressure water chamber consists of three parts: an inlet water chamber, an intermediate water chamber and an outlet water chamber, wherein the intermediate water chamber is two process coolant mixing chambers. The heat transfer tube structure is simulated by seven control bodies. The first and second flow heat transfer tubes are composed of three control bodies. The three control bodies correspond to the rising, horizontal and descending sections. The intermediate water chamber is simulated by a control body, which connects a flow of descending channels and the second process of rising channels [4]. The secondary model is composed of water supply control body, cylinder body control body, steam water separation device control body and the second loop hot trap control body [5]. The control body of the left steam generator is shown in Figure 1.

\section{Impact Analysis of Breakage Size}

\subsection{Experimental Conditions}

\subsubsection{Experimental Purposes}

This experiment is to analyze the small fault accident process of single-port evaporator single heat transfer tube, focusing on the failure of the fault circuit cannot be isolated when the heat transfer tube small break happens, and find the different size of the break to the impact of the accident process, aimed at improving the operation of the small breakage accident awareness, and improving the ability to deal with accidents, especially when the loop cannot be effectively isolated.

\subsubsection{Calculation Conditions}

Heat pipe small break accident analysis and calculation conditions:

1) $86 \%$ rated power operating conditions;

2) Single heat transfer tube break size of $2 \mathrm{~mm}$ and $6 \mathrm{~mm}$;

3) Steam release valve, safety valve, spray valve, fill pump conditions are setting automatically;

4) The safe injection system condition is setting automatically. 


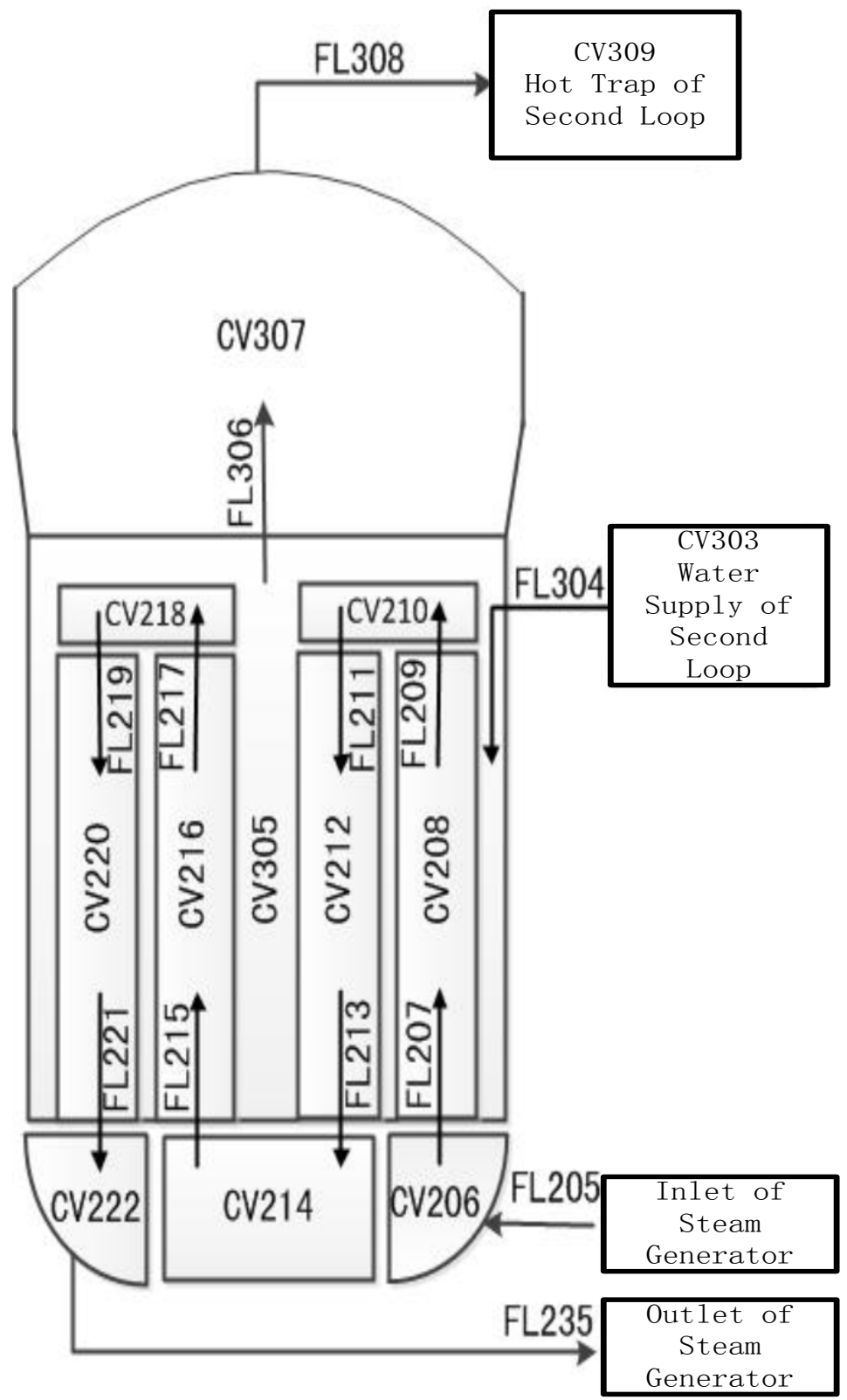

Figure 1. Control body chart of steam generator.

\subsubsection{The Sequence of Human Intervention Events}

The sequence of human intervention events is assumed based on safety analysis results and real ship operating procedures:

1) The operators confirm $2 \#$ evaporator heat pipe damage occurred when small break accident has occurred $60 \mathrm{~s}$, and at the same time the following operations are taken: closing 2\# and 4\# main gate valve, isolating reactor left loop; dropping down reactor power; closing the bulk vessel steam bridge valve, closing the left side steam compartment valve;

2) The steam bridge valve and the left side of the steam compartment valve are closed when small break has occurred $70 \mathrm{~s}$; at the same time, the reactor power has dropped down to $22 \%$ rated power condition; 
3) The left main pump is stopped when small break has occurred $90 \mathrm{~s}$;

4) It is found that the left loop cannot be effectively isolated when small break occurred at $120 \mathrm{~s}$, and then the reactor is shutdown.

\subsection{Analysis of the Impact of Different Break Size}

Carrying out a single port (left side) evaporator single heat transfer tube small break analysis by setting $2 \mathrm{~mm}$ and $6 \mathrm{~mm}$ two break size and comparing the impact of different break size on the accident process, when the critical cooling system is not put in.

\subsubsection{Influence of Different Size Damage of Heat Transfer Tubes on Reactor Power}

The reactor power changes are shown in Figure 2 under the heat transfer tube small break accident. The small break accident is inserted at $500 \mathrm{~s}$, the black solid line is for the $2 \mathrm{~mm}$ break size accident, and the black dotted line is for $6 \mathrm{~mm}$ break size accident. It can be seen from the figure, the reactor power changes are basically the same under the two break size, and the curve is basically coincident. The reactor power is stable at $86 \%$ rated power before the time of $500 \mathrm{~s}$. A small break accident is inserted at the time of $500 \mathrm{~s}, 60$ seconds later, the operators determine the nature of the accident and the accident point, and then they begin to drop down the reactor power, 10 seconds later the reactor power is dropped down to $22 \%$ rated power, and then they begin to treat the accident. After that, for about 50 seconds, the reactor power is dropping down slightly, but it is stable at $22 \%$ rated power level basically. The operators determine that the left loop (broken circuit) cannot be effectively isolated after the accident occurred $120 \mathrm{~s}$, then they begin to shutdown the reactor. The reactor power quickly dropped to the shutdown power level.

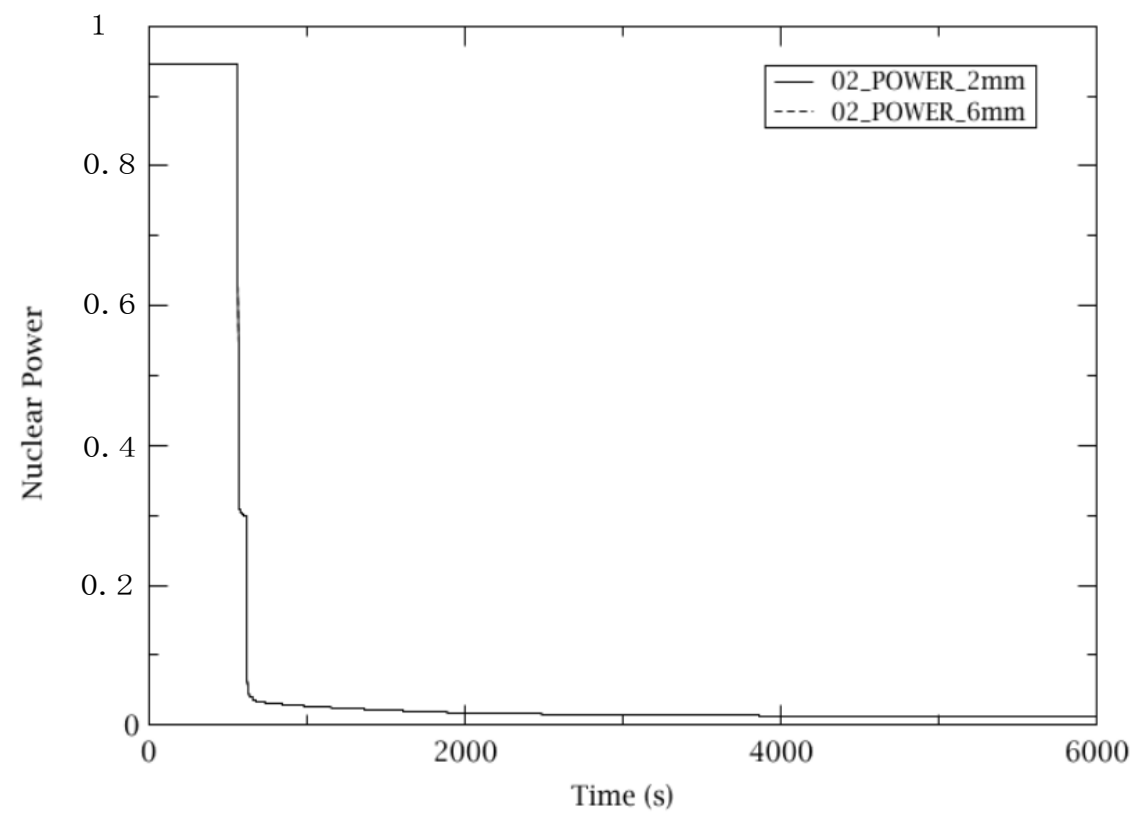

Figure 2. Reactor power changes under small break accident of heat transfer tube. 


\subsubsection{Influence of Different Size Break Accident of Heat Transfer Tube on Loop Pressure}

The primary loop pressure changes are shown in Figure 3 under heat transfer tube small break accident. The left side of the evaporator single heat pipe small break accident is inserted at the time of $500 \mathrm{~s}$. The broken sizes are $2 \mathrm{~mm}$ and 6 $\mathrm{mm}$, the black solid line is for $2 \mathrm{~mm}$ break, and the black dotted line is for the 6 mm break.

After the accident occurred, the high-temperature and high-pressure water of heat transfer tube primary side leaks to the secondary side resulting in the loss of water and the increased heat transfer. The reactor power is dropping down after time of $60 \mathrm{~s}$, under the combined effects; the primary loop pressure is dropped down to the local minimum point at the time of $76.56 \mathrm{~s}$. The primary loop pressure is dropped to 0.68 under $2 \mathrm{~mm}$ break, and the pressure is dropped to 0.67 under $6 \mathrm{~mm}$ break. After 50 seconds of that time, the primary pressure begins to increase because of the shutdown of the steam bridge valve, the left side of the steam compartment valve and the left side of the main pump. The reactor power cannot be successfully transmitted to the secondary circuit, and the pressure begins to rise to the local maximum pressure at the time of $126.30 \mathrm{~s}$ after accident occurred. The primary loop pressure rises to 0.78 under $2 \mathrm{~mm}$ break, and the pressure rises to 0.74 under $6 \mathrm{~mm}$ break. 120 seconds after the accident occurred, the reactor is shutdown. Because of the impact of shutdown, the primary loop pressure begins to decline, but the downward trends of $2 \mathrm{~mm}$ break and 6 $\mathrm{mm}$ break are different: Under the $6 \mathrm{~mm}$ break the broken size is larger, and the broken flow is larger. The broken water flow can take away the remaining heat of the core. $3506.31 \mathrm{~s}$ after the accident occurred, the pressure drops to safe injection pressure. The break size is smaller, and the broken flow is smaller under

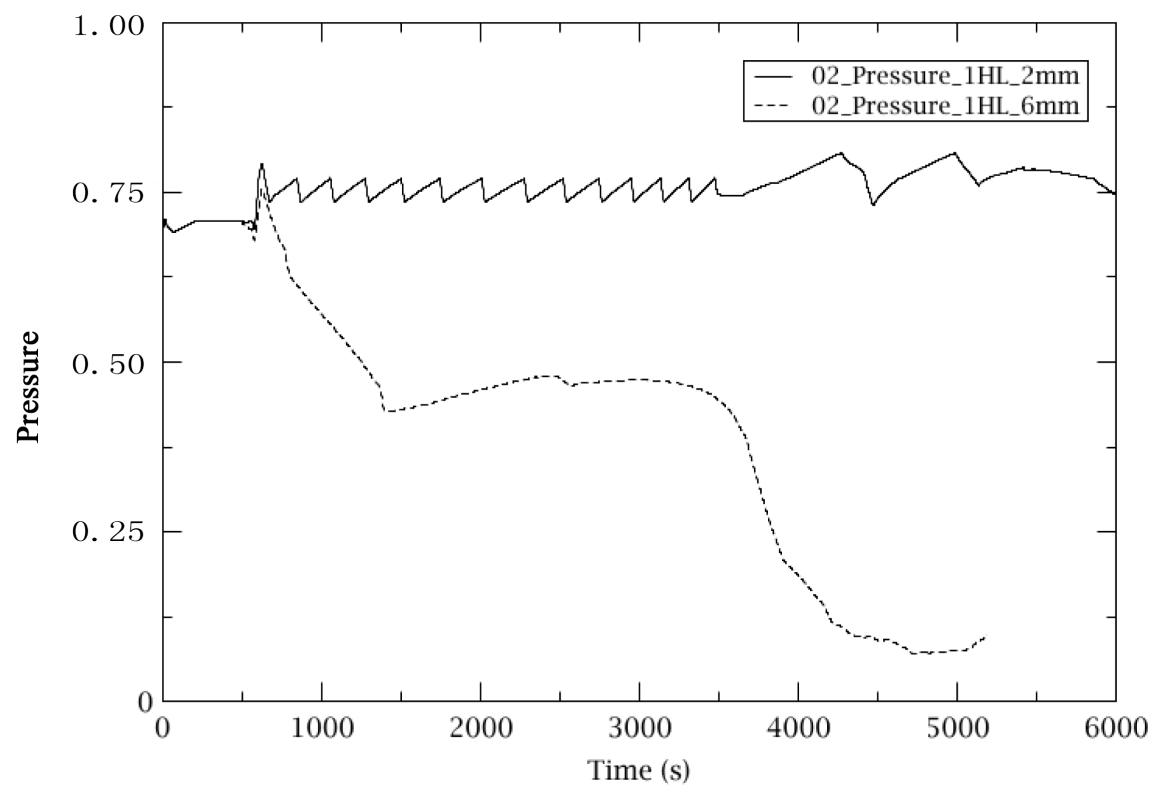

Figure 3. The change of the primary pressure under the small break accident of heat transfer tube. 
$2 \mathrm{~mm}$ break accident. The broken water flow cannot effectively take away the remaining heat of the core. The loop pressure begins to rise at $335.70 \mathrm{~s}$ after the accident occurred; the pressure reaches to the regulator release valve opening pressure. Under the control of the release valve, the primary pressure shocks at 0.75 , but at the time of $3770.57 \mathrm{~s}$ after the accident occurred, the pressure reaches to the regulator safety valve opening pressure, the safety valve opens to relief pressure, but it still cannot make the pressure effective down. At 10,000 s, the primary pressure is still 0.67 .

In view of the above, the primary loop pressure is kept stable under the control of the regulator release valve and the safety valve under the $2 \mathrm{~mm}$ break accident. The pressure is slowly down under the $6 \mathrm{~mm}$ break accident, but the descent rate is slow, the pressure reaches to low-pressure safe injection condition.

\subsubsection{Influence of Different Size Damage of Heat Transfer Tubes on Water Level of Regulator}

Regulator water level changes are shown in Figure 4 under the heat transfer tube small break accident, the left steam generator single heat transfer tube small break is inserted at the time of $500 \mathrm{~s}$. Broken sizes are $2 \mathrm{~mm}$ and $6 \mathrm{~mm}$, the black solid line is for $2 \mathrm{~mm}$ break, the black dotted line is for $6 \mathrm{~mm}$ break.

After the heat transfer tube damaged, the main circuit coolant leaks to the secondary side of the evaporator under the influence of the huge pressure difference between the two sides of the tube, the leakage flow is larger, the water of the primary circuit losses, the water level of the regulator drops. $75.69 \mathrm{~s}$ after the accident, 808 water level drops to the local minimum, $2 \mathrm{~mm}$ broken water level drops to $0.47,6 \mathrm{~mm}$ broken water downs to 0.39 . After that, the regulator water

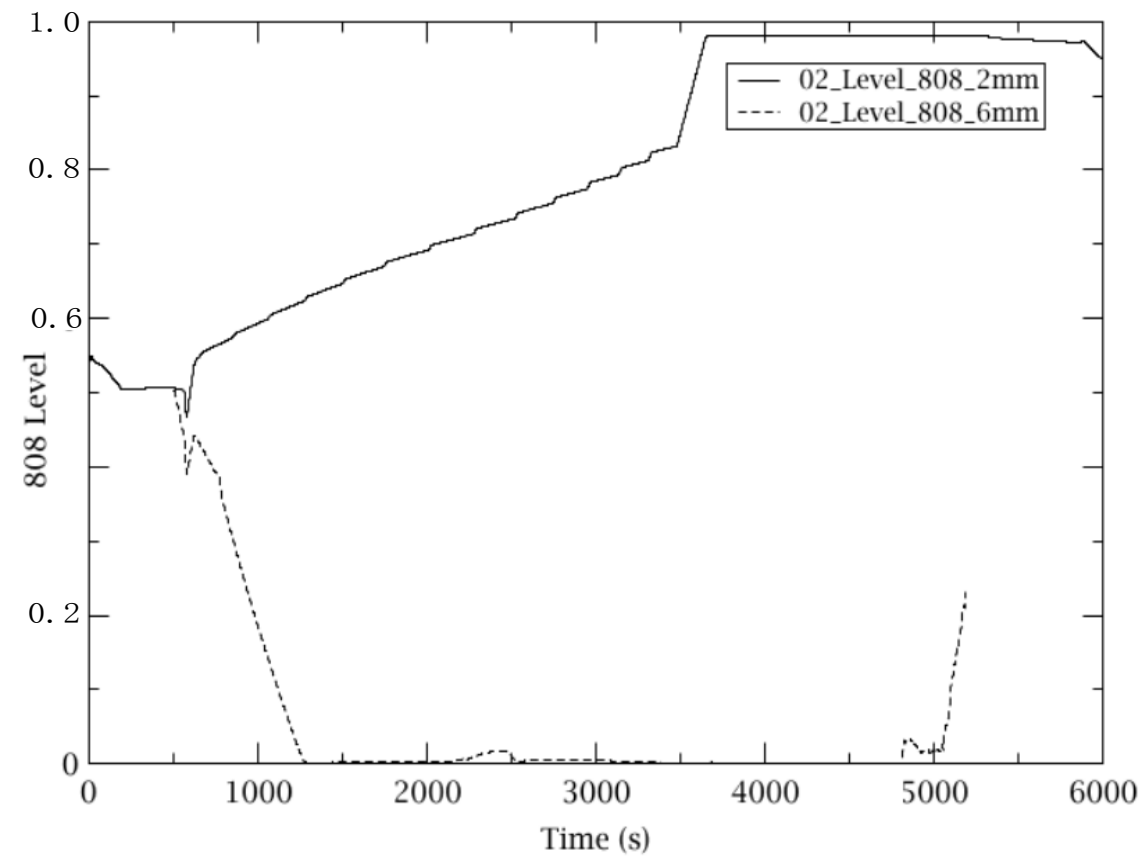

Figure 4. The change of water level of regulator under small break of heat transfer tube. 
level begins to rise because of the reasons of the reactor power dropping down, replenishment pump replenishing water, broken flow dropping down by steam pipe isolation and other comprehensive role. $127.27 \mathrm{~s}$ after the accident, $2 \mathrm{~mm}$ break 808 water level rises to $0.54,6 \mathrm{~mm}$ broken 808 water level rises to 0.44 .

After that, the 808 water level changes under the $2 \mathrm{~mm}$ break and $6 \mathrm{~mm}$ break are different. Under $2 \mathrm{~mm}$ break, broken flow is small, although the reactor is shutdown lately, but the crisis cooling system is not put into the reactor, the remaining heat release cannot be successfully derived, the Loop and regulator temperatures rise resulting in 808 water level rises continuously, at $3153.58 \mathrm{~s}$, 808 is full of water; Under the $6 \mathrm{~mm}$ break, broken flow is larger, the water can take away the remaining heat of the core, plus the reactor shutdown, the circuit temperature drops, 808 water level declines continuously, $772.10 \mathrm{~s}$ after the accident, 808 water level drops to zero. $4375.73 \mathrm{~s}$ after the accident occurred, 808 water level begins to rise because of the input of low pressure injection system.

In summary, the 808 water level changes are different under the $2 \mathrm{~mm}$ break and the $6 \mathrm{~mm}$ break. The fundamental reason is whether the broken flow can take away the remaining heat of the core. The broken flow is smaller under small size break, the capacity to takeout the core heat is limited, eventually leading to 808 full of water; The broken flow is larger under larger size break, it can take away the remaining heat release of the core, resulting in 808 water zero level. The larger size break can drop down the circuit pressure to the safety system injection pressure, and makes up for the loss of leakage, so that the 808 water level increases.

\subsubsection{Influence of Different Size Damage of Heat Transfer Tubes on Water Level of Core}

The left steam generator single heat transfer tube small break is inserted at the time of $500 \mathrm{~s}$. Broken sizes are $2 \mathrm{~mm}$ and $6 \mathrm{~mm}$, the black solid line is for $2 \mathrm{~mm}$ break, the black dotted line is for $6 \mathrm{~mm}$ break. Black solid line in Figure 5 is for first process water level changes of core under $2 \mathrm{~mm}$ break accident, black dotted line in Figure 5 is for first process water level changes of core under $6 \mathrm{~mm}$ break accident; black solid line in Figure 6 is for second process water level changes of core under $2 \mathrm{~mm}$ break accident, black dotted line in Figure 6 is for second process water level changes of core under $6 \mathrm{~mm}$ break accident.

After the accident occurred, before $1724.84 \mathrm{~s}$, whether it is $2 \mathrm{~mm}$ or $6 \mathrm{~mm}$ size break, the first process water level of core is full, but from $1724.84 \mathrm{~s}$ under $6 \mathrm{~mm}$ size break, the first process water level begins to decline, at the time of $3201.96 \mathrm{~s}$, the level reaches to zero. From $3437.25 \mathrm{~s}$, the level begins to rise, and at the time of $4296.16 \mathrm{~s}$, the first process water level of core rises to 0.62 .

After the accident occurred, before $4496.08 \mathrm{~s}$, under the $2 \mathrm{~mm}$ size break accident, the first process water level of core is basically full. From $4496.08 \mathrm{~s}$ under $2 \mathrm{~mm}$ size break accident, the first process water level begins to decline, at the time of $5511.11 \mathrm{~s}$, the level reaches to zero. From then, the first process water level of core under $2 \mathrm{~mm}$ size break accident doesn't raise again. 


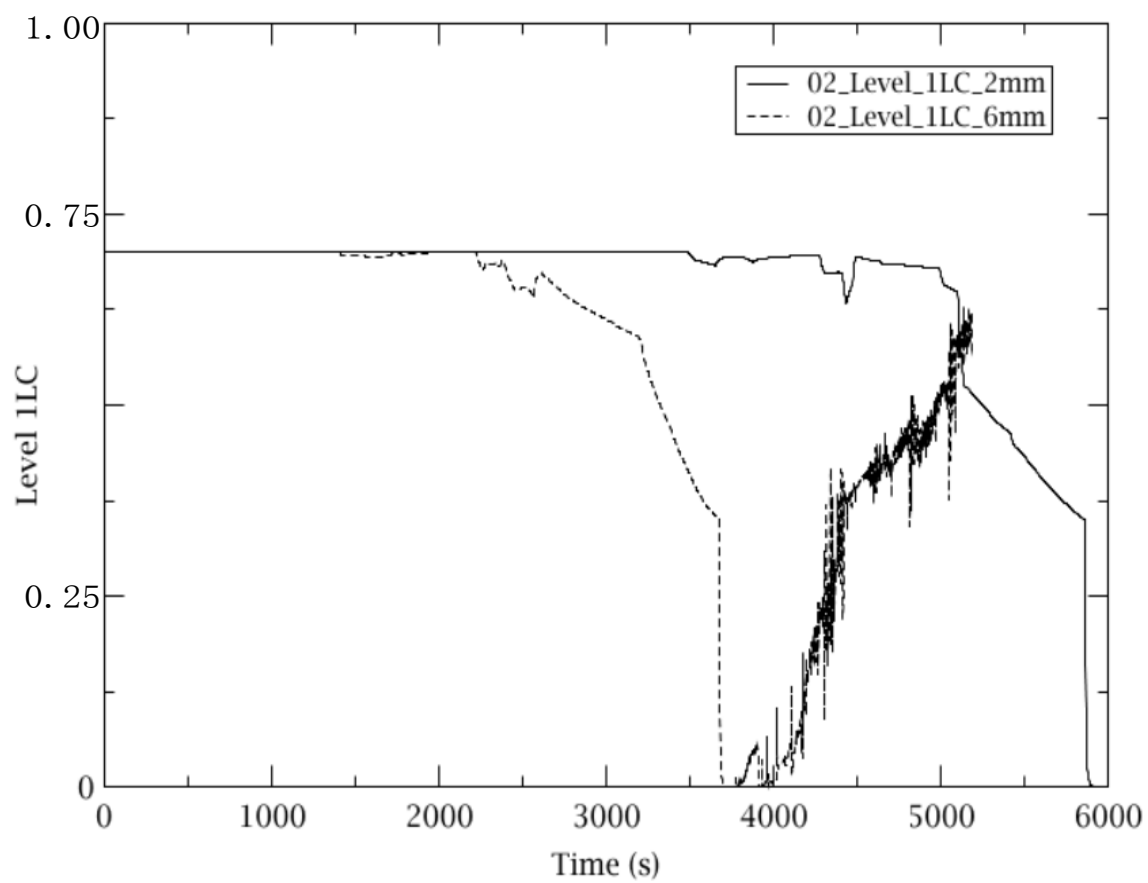

Figure 5. Water level changes of first process in core under the heat transfer tube break accident.

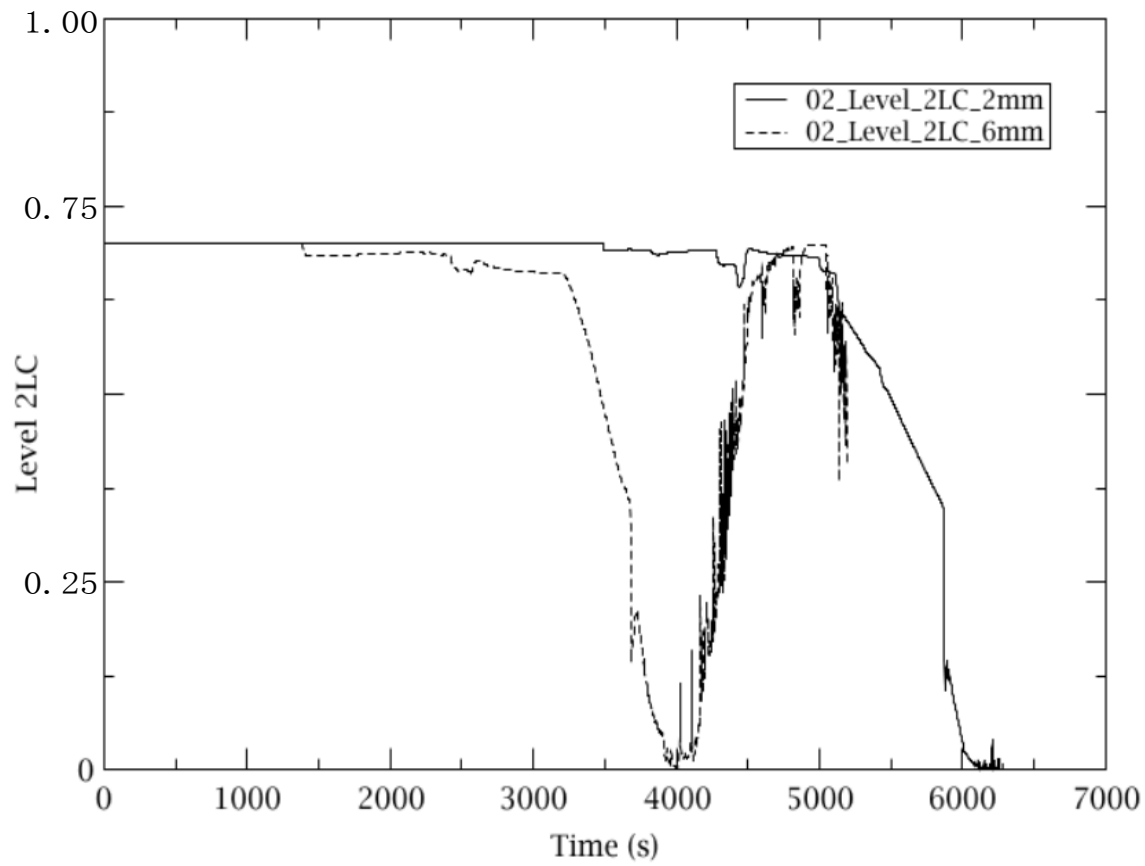

Figure 6. Water level changes of second process in core under the heat transfer tube break accident.

After the accident occurred, before $897.71 \mathrm{~s}$, whether it is $2 \mathrm{~mm}$ or $6 \mathrm{~mm}$ size break accident, the second process water level of core is full, but from $897.71 \mathrm{~s}$ under $6 \mathrm{~mm}$ size break, the second process water level begins to decline, at the time of $3494.12 \mathrm{~s}$, the level reaches to zero. From $3608.25 \mathrm{~s}$, the level begins to 
rise, and at the time of $4317.65 \mathrm{~s}$, the second process water level of core rises to 0.70 .

After the accident occurred, before $4489.22 \mathrm{~s}$, under the $2 \mathrm{~mm}$ size break accident, the second process water level of core is basically full. From $4489.22 \mathrm{~s}$ under $2 \mathrm{~mm}$ size break accident, the second process water level begins to decline, at the time of $5598.69 \mathrm{~s}$, the level reaches to zero. From then, the second process water level doesn't rise again.

In summary, whether it is $2 \mathrm{~mm}$ or $6 \mathrm{~mm}$ size break, the accident will cause the decline of first and second processes water level of core, and even cause the core one or two processes exposed. Under the $6 \mathrm{~mm}$ size break, the first process exposure time is $3201.96 \mathrm{~s}$ after the accident happened; the second process exposure time is $3494.12 \mathrm{~s}$ after the accident happened. Under the $2 \mathrm{~mm}$ size break, the first process exposure time is $5511.11 \mathrm{~s}$ after the accident happened; the second process exposure time is $5598.69 \mathrm{~s}$ after the accident happened.

\subsubsection{Influence of Different Size Damage of Heat Transfer Tubes on Steam Pressure}

The left steam generator single heat transfer tube small break accident is inserted at the time of $500 \mathrm{~s}$. Broken sizes are $2 \mathrm{~mm}$ and $6 \mathrm{~mm}$, the black solid line in Figure 7 is for evaporator steam pressure changes under $2 \mathrm{~mm}$ size break, the black dotted line is for evaporator steam pressure changes under $6 \mathrm{~mm}$ break.

At the time of $60 \mathrm{~s}$ after the accident occurred, the steam bridge valve and the left side of steam compartment valve begin to close, at the time of $70 \mathrm{~s}$, the valves are closed. Due to the closure of the bridge valve and the compartment valve, the steam of the left side is in the closed state, the steam pressure suddenly surges at

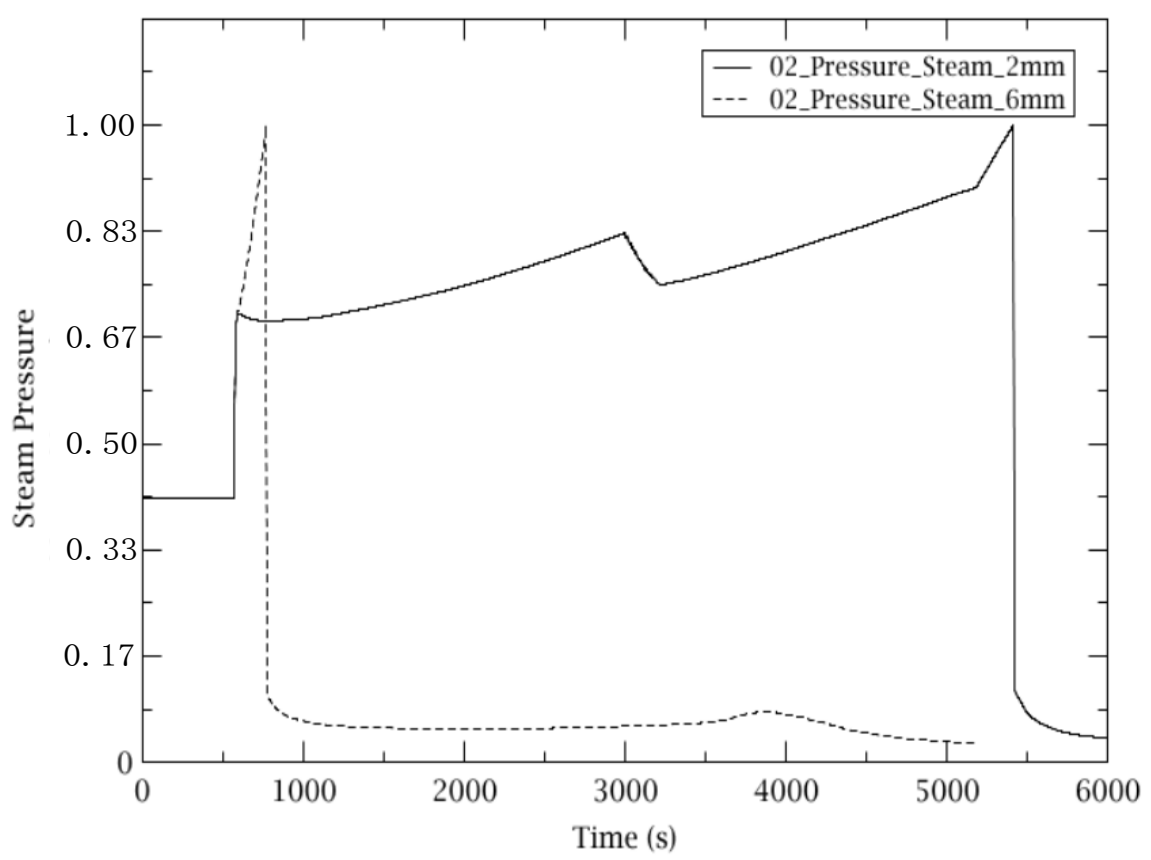

Figure 7. Steam pressure changes in broken evaporator under heat transfer tube breakage accident. 
$75.16 \mathrm{~s}$. At $81.41 \mathrm{~s}$ after the accident occurred, the steam pressure rises to 0.71 under $2 \mathrm{~mm}$ and $6 \mathrm{~mm}$ size break. After that, the steam pressure under $2 \mathrm{~mm}$ break is slowly rising. However, at $4918.10 \mathrm{~s}$, the steam pressure reaches the pipeline breakage pressure, the pipeline is broken, and then, steam pressure decreases rapidly. The broken size is larger under $6 \mathrm{~mm}$ break, huge broken flow brings a lot of heat, the steam pressure rises sharply. After only $254.65 \mathrm{~s}$, the accident causes the pipeline rupture, the steam pressure declines rapidly.

In summary, in the absence of a critical cooling system, whether it is $2 \mathrm{~mm}$ or $6 \mathrm{~mm}$ broken size, the accident will cause the steam pressure reach the broken pressure, and lead to the rupture of pipe between evaporator and the compartment valve.

\subsubsection{Influence of Different Size Damage of Heat Transfer Tubes on Broken Flow}

The left steam generator single heat transfer tube small break accident is inserted at the time of $500 \mathrm{~s}$. Broken sizes are $2 \mathrm{~mm}$ and $6 \mathrm{~mm}$, the black solid line in Figure 8 is for broken flow changes under $2 \mathrm{~mm}$ size break, the black dotted line is for broken flow changes under $6 \mathrm{~mm}$ size break.

The $2 \mathrm{~mm}$ break is small, and under the pressure difference between the first side and second side, the broken flow is basically maintained at 0.075 . Under the $6 \mathrm{~mm}$ size break, the pressure difference between the first side and second side is huge, the broken flow rate increases from zero to 0.89 , and then due to the pressure decrease of primary loop, and the closure of bridge valve and compartment valve, the vapor pressure of the secondary side gradually increases, resulting in the decrease of pressure difference between the first side and second side. The broken flow gradually reduces, the broken flow drops down to the local minimum

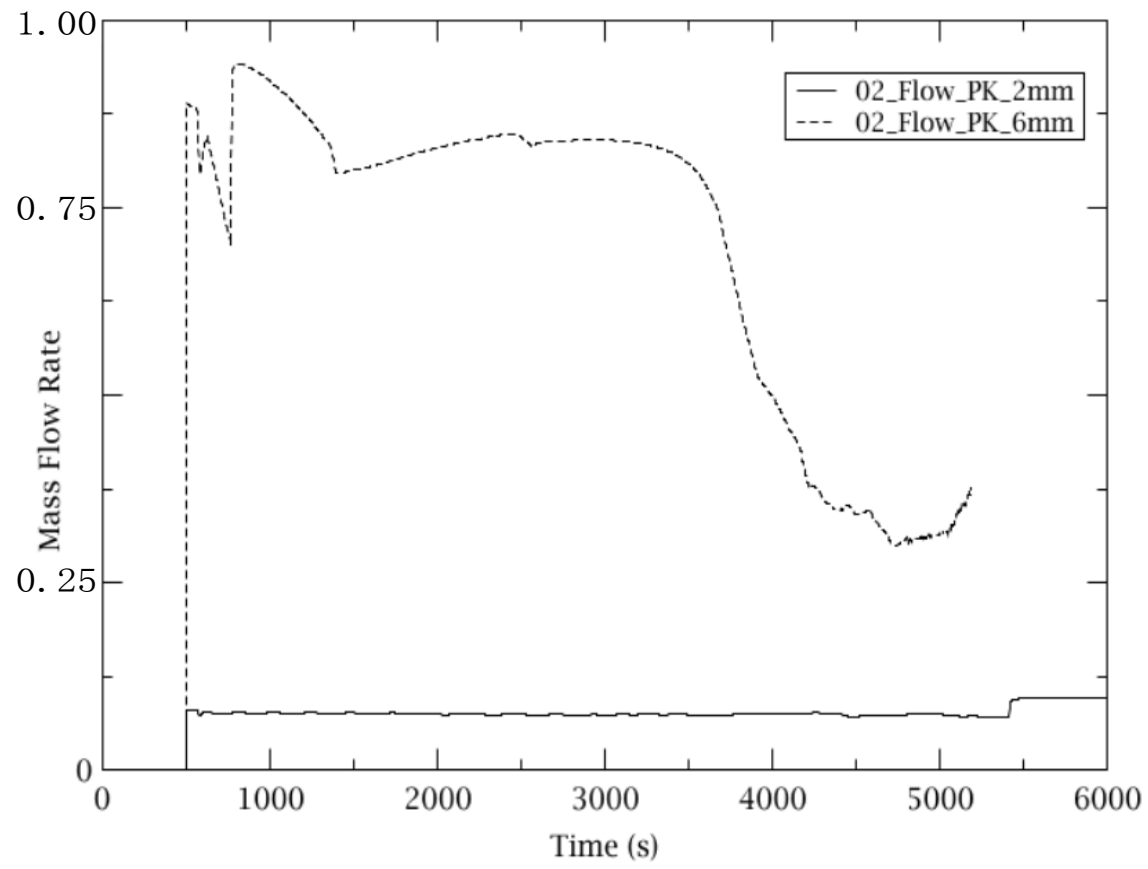

Figure 8. The change of broken flow in heat transfer tube break accident. 
of 0.70 . The pipeline ruptures after that, resulting in the rapid pressure decrease of second side, the pressure difference between the first side and second side increases, and the broken flow surges to 0.94 . Then due to the pressure reduction of primary loop, the broken flow is also gradually reduced to the minimum of 0.31 at the time of $4225.49 \mathrm{~s}$ after the accident.

It can be seen from the above analysis, $2 \mathrm{~mm}$ break is small, the pressure changes between the first side and second side have small influence on broken flow, the broken flow remains stable; $6 \mathrm{~mm}$ size break is larger, the pressure changes between the first side and second side have big influence on broken flow, the broken flow changes frequently, but the overall trend of flow is still down.

\subsubsection{Influence of Different Size Damage of Heat Transfer Tubes on Damage Time of Fuel Element Enclosure}

Through the analysis of the small break, it can be seen that under the condition of no critical cooling system, the damage time of the shell under the $2 \mathrm{~mm}$ break is $6388.50 \mathrm{~s}$, and the damage time of the shell under the $6 \mathrm{~mm}$ break is $4160.32 \mathrm{~s}$.

\section{Conclusions}

In this paper, the damage analysis of the heat transfer tube under the condition that the damage circuit cannot be isolated is analyzed. By comparing and analyzing the accident consequences of $2 \mathrm{~mm}$ and $6 \mathrm{~mm}$ damage, the following conclusions can be drawn:

1) Smaller break is difficult to effectively take away the core heat through the broken water flow, and the small size break accident will cause the regulator full of water;

2) Whether it is a small size break, or a larger size break under the condition of the closure of the bridge valve and the compartment valve, the small break accident will cause damage to the pipeline. So, additional safety valve should be added to release the pressure;

3) In the case of the broken circuit cannot be isolated, the smaller break and the larger break size accidents will cause the core exposed, threatening the safety of the reactor;

4) In the case of the broken circuit cannot be isolated, the smaller size break and larger size break accidents will cause damage to the fuel element cladding, and the radioactive material will release.

In this paper, the damage analysis of the heat transfer tube under the condition of non-isolation of the loop is carried out. The simulation of the different break size is used to analysis the accident process and the consequence, and the awareness of the break size influence on the damage consequence of the heat transfer tube is improved; the analysis and handling capacity of the damaged tube of the heat transfer tube is improved; the reactor accident handling capacity under the condition of the damage of the heat transfer tube is also improved. 


\section{References}

[1] Nuclear Regulatory Commission (1988) NRC Integrated Program for the Resolution of Unresolved Safety Issues A-3, A-4, and A-5 Regarding Steam Generator Tube Integrity, NUREG-0844. Nuclear Regulatory Commission, US.

[2] Carazas, F.J.G., Salazar, C.H. and Souza, G.F.M. (2011) Availability Analysis of Heat Steam Generators Used in Thermal Power Plants. Energy, 30, 3855-3970. https://doi.org/10.1016/j.energy.2010.10.003

[3] Allison, C.M. (1992) RELAP5/MOD3 Code Manual, NUREG/CR-5535. Idaho National Engineering Laboratory, US.

[4] Herbert, S.W. (1982) Dynamic Modeling of Vertical U-Tube Steam Generators for Operational Safety Systems. MIT, USA.

[5] Bao, J., Sun, B.Z. and Zhang, G.L. (2012) Simulation and Analysis of Steam Generator Water Level Based on Nonlinear Model. 2012 Asia-Pacific Power and Energy Engineering Conference, Shanghai, 27-29 March 2012, 1-3. 